\title{
Adaptation pathways and path dependencies: Insights into past and future decision-making in flood risk management
}

\author{
Christoph Clar ${ }^{1}$, Susanne Hanger-Kopp ${ }^{2}$, Thomas Schinko², Sebastian Seebauer ${ }^{3}$ and Thomas Thaler 2 ,a \\ ${ }^{1}$ Institute for Mountain Risk Engineering, BOKU University of Natural Resources and Life Sciences, Vienna, Austria \\ 2 Population and Just Societies Program, IIASA International Institute for Applied Systems Analysis, Laxenburg, Austria \\ ${ }^{3}$ LIFE - Centre for Climate, Energy and Society, JOANNEUM RESEARCH Forschungsgesellschaft mbh, Graz, Austria
}

\begin{abstract}
Recent extreme flood events show that the challenges posed by climate-related risks demand well-informed and -prepared local planning and governance. Consequently, the main political and academic discourse revolves around developing approaches that make society more resilient against potential future events not just by introducing smart technical solutions, but also by improving and strengthening local decision-making processes. Nonetheless, flood risk management decisions and their impacts are typically developed as a response to a singular past flood event, often overlooking the locally specific social and economic framework-conditions. Hence, alternative management options are often not considered within the decision-making process, although the decision might have long-term impacts. The paper analyzes the long-term development and impacts of decision-making arenas in which local adaptation policy evolves and assesses the impacts on flood risk management. These arenas are characterized by (1) competing interests from various policy areas, (2) ad-hoc decisions often taking precedence over strategic planning for long-term climate risk management, and (3) previous decisions providing carry-over, follow-up or even creating lock-in effects for later decisions. We propose a novel approach that brings together the broad range of knowledge about path dependencies with ongoing scholarly debates on adaptation pathways in flood risk management. This enables us to combine backwards- with forward-looking perspectives and, thus, both analyze past and support (possible) future decisionmaking. Our case studies are located in two Austrian climate change adaptation regions. There, we identify intersecting pathways of how hazards and socio-economic conditions developed over time and identify crucial points in time in which major decisions were made. This allows us to trace past pathways that lead to particular constellations and situations in which a specific pathway is chosen over other alternatives. We argue that learning from these past experiences lays the foundation for the development of socioeconomically and politically feasible flood risk management pathways for the future.
\end{abstract}

\section{Introduction}

Recent extreme flood events show that the challenges posed by climate-related risks demand well-informed and -prepared local planning and governance. Consequently, in addition to the development of smart technical solutions, academic discourses increasingly focus on the development of approaches that make society more resilient against potential future events by improving decision-making processes, especially at the local level. However, practice is often lagging behind. Austria is an illustrative example for how despite these academic developments, flood risk management (FRM) practices are mostly dominated by geosciences and engineering approaches (Papathoma-Köhle et al. 2017; Sturm et al. 2018), where risk reduction schemes revolve around insurance and damage compensation (Prettenthaler et al. 2015, Seebauer \& Babcicky 2016). In this regard, FRM decisions and their impacts are still being assessed as singular events, locally specific social and economic framework-conditions are often neglected, and alternative paths and decisions that have not been taken into account so far hardly have a chance to get onto the agenda. Despite these hindering path dependencies, the call of scholars and policy makers for the development of appropriate and more resilient risk governance arrangements is growing louder (Seebauer et al. 2019; Thaler et al. 2019). This refers to the role of traditional governmental actors (Clar 2019), but also includes more innovative public-privatecivil society partnerships (Seebauer et al. 2019; Thaler \& Seebauer 2019) and stronger social arrangements for flood protection and the promotion of private flood preparedness (Babcicky \& Seebauer 2017).

Perhaps the most well-known attempt to facilitate adaptation planning in FRM under the influence of climate change is the adaptation pathways approach (APA;

\footnotetext{
a Corresponding author: thomas.thaler@boku.ac.at

DOI 10.3311/FLOODRisk2020.25.6
} 
Haasnoot et al. 2013, 2012; Ranger et al. 2013; Wise et al. 2014; Hanger-Kopp et al. forthcoming). However, despite its broad establishment and its inspiring advancement, the Dynamic Adaptive Policy Pathways approach (DAPP; Haasnoot et al. 2013), it does not seem to be equipped to deal with the great uncertainties resulting from climate change-induced changes local planning and governance are challenged with. Current applied adaptation pathways literature (Zandvoort et al. 2017; Bloemen et al. 2018) helps us to assess and learn from past decision-making processes for the development of robust future pathways under climate change uncertainty, whereas the DAPP allows us to use the current situation, objectives and uncertainties as starting point for developing forwardlooking pathways. However, as the authors of this article show in Hanger-Kopp et al. (forthcoming), there lies much more potential especially in literature on path dependencies that has not been harnessed yet. Referring to two case studies in Austria, in this contribution, we outline a new approach that aims to fill this gap by integrating the path dependency concept with state of the art-research on adaptation pathways. In this contribution, we aim to follow this call and expand the current narrow perspective on FRM practices by integrating backward- and forwardlooking perspectives in a novel approach, which enables theory and practice alike to include past historical views, social learning effects, triggers of key developments, decision points and transdisciplinary research into FRM assessment and planning.

After an introduction to the shortcomings of the adaptation pathways approach with reference to the case of Austrian FRM, we illustrate how adaptation pathways may contribute to revealing or anticipating path dependencies. This insight prepares the following two case studies at the local level in Austria. This early application of our novel approach allows us to provide first insights into and draw first conclusions about its potential for theory and practice of FRM.

\section{The adaptation pathways approach and its shortcomings in flood risk management for the case of Austria}

The APA has become increasingly popular for adaptation planning under deep uncertainty (Haasnoot et al. 2012, 2013; Ranger et al. 2013; Wise et al. 2014). It belongs to the family of adaptive planning approaches and refers to pathways as sequences of adaptation measures. Its key innovation are decision or tipping points, also known as sell-by-date of an adaptation measure. Once adaptation measures no longer fulfil a predetermined minimum performance level, for instance certain safety standards or risk levels, the pathway reaches a tipping point where further action must be taken or a new pathway chosen. However, considering long-term developments need not be restricted to adaptation measures or hazards, but should also include parallel intersecting processes such as changes in the exposure of humans and assets, or in the financial budget available to authorities tasked with mitigating flood impacts.
Within intersecting pathways of how extreme events and socio-economic conditions developed over time, the identification of decision points allows us to trace pathways that lead to particular moments in time when a specific pathway is chosen over other possible pathways. Figure 1 shows how different pathways intersect, including the significance of decision points for further developments.

At these decision points, public authorities need to take adaptation actions as their current management approaches have failed or proved insufficient (Kwadijk et al. 2010). While these decisions can also be made implicitly, e.g. by ignoring available options and taking no action, adaptation pathways literature mostly focuses on explicit decisions, e.g. a resolution of the municipal council or the formal passing of a risk management plan pursuant to the EU Floods Directive.

We build on the well-established adaptation pathways approach (APA; Haasnoot et al. 2013) and expand it based on current applied adaptation pathways literature (Zandvoort et al. 2017; Bloemen et al. 2018). It allows us to learn from past decision-making processes for the development of robust future pathways under climate change uncertainty. The Dynamic Adaptive Policy Pathways (DAPP) approach (Haasnoot et al. 2013) uses the current situation, objectives and uncertainties as starting point for developing forward-looking pathways. We argue that looking back 15-30 years helps to better understand the local decision-making processes and general framework conditions, which in turn allows the codevelopment of more robust forward-looking adaptation pathways. In particular, we suggest to critically reflect on why at specific decision points in the past some adaptation options were chosen while others were postponed, discarded or neglected, and how the selected options set the stage for ensuing developments. This innovative, counterfactual approach illustrates and explains sciencepractice gaps in adaptation decision-making (Clar 2019). Complementary to learning from the past, looking forward 10-20 years helps to anticipate unintended or maladaptive consequences and points out no-regret options within an inherently uncertain decision-making arena. Hence, linking the past with the future allows elaborating critical dynamics in FRM that may be generalised and transferred to other regions and countries. Incorporating the proposed counterfactual backward looking approach into the established adaptation pathways methodology, further improves robust planning under deep uncertainties.

Within the application of the APA, fostering a transdisciplinary learning process allows to generate a systematic understanding of current developments and to elaborate future visions and solutions (Stauffacher et al. 2008; Fuchs \& Thaler 2017), which is crucial for expanding the current engineering-based FRM approach in Austria. This knowledge-based, participatory approach can promote social learning in order to understand how resilient adaptation pathways can be triggered and facilitated. For instance, disaster events often provide a tipping point or window of opportunity to initiate largescale adaptation efforts, which may lead to transformative change (Kates et al. 2012; Clar \& Steurer 2019). However, ad-hoc decisions might cause maladaptation and result in 


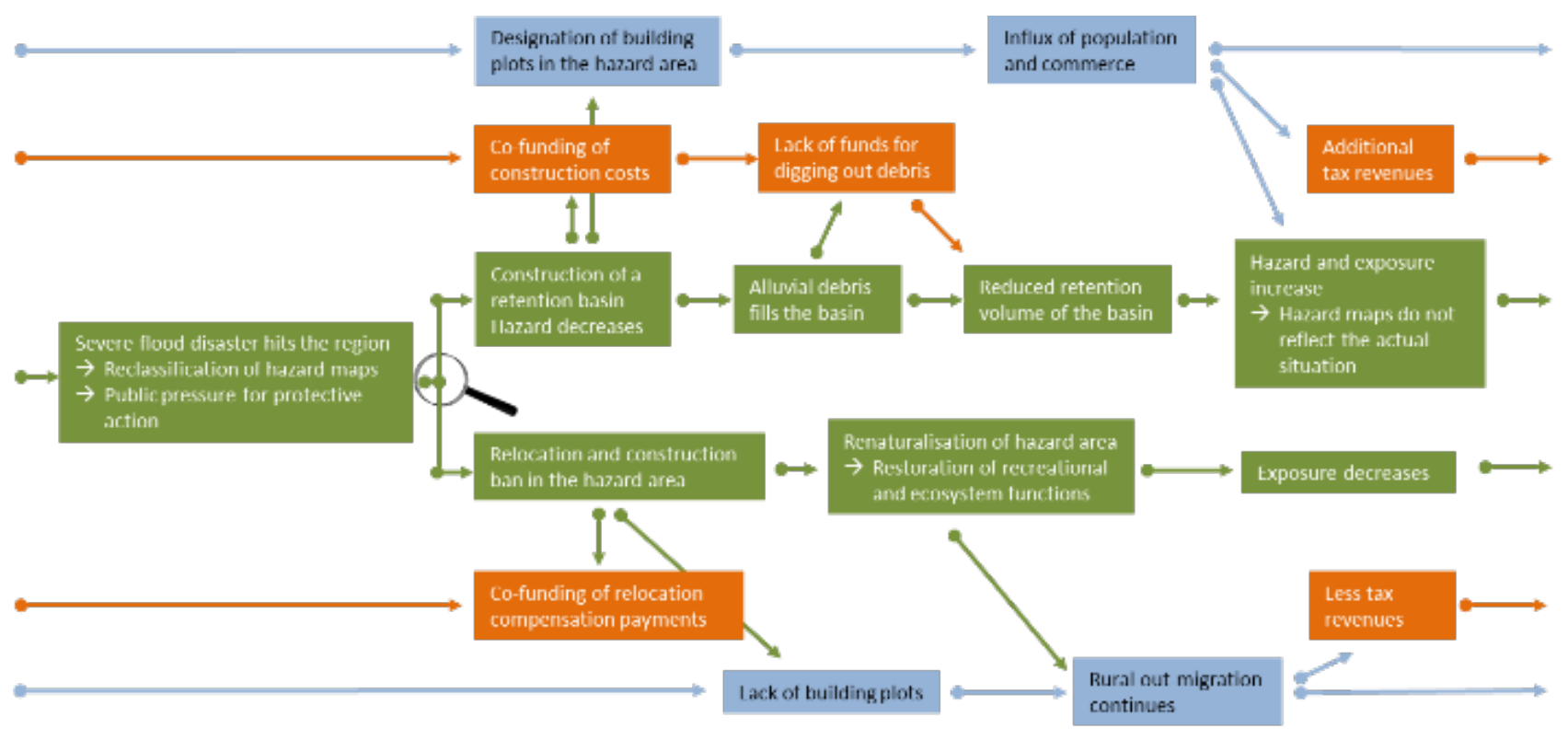

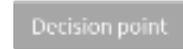

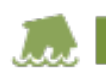

Hazard pathway

Figure 1. Simplified representation of pathways in a retention basin vs. relocation decision.

lock-in, such as over-reliance on technical mitigation measures or lack of targeted land use planning (Tarlock 2012; Collenteur et al. 2014; Fuchs et al. 2017). Only by including concerned stakeholders not just as spectators and commentators, but as participants and co-producers of relevant policy decisions (Tseng \& Penning-Rowsell 2012; Seebauer et al. 2019), a balanced set of recommendations can be achieved in practice.

\section{The ability of adaptation pathways to reveal or anticipate path dependencies}

Under deep uncertainty, as in the case of climate change-related changes in FRM, it is crucial for decisionmaking to consider several pathways, address alternative scenarios and strategies (Ciullo et al. 2020). In the application of the APA, decision trees or roadmaps show several feasible sequences and thus allow reassessment of adaptation needs at strategic points in the future, accounting for new and potentially better information. While the traditional APA ends with evaluation and path development, Haasnoot et al. (2013) propose to incorporate monitoring and contingency actions from dynamic adaptive policy making and create an extended dynamic adaptive policy pathways approach (DAAP). This allows adaptation plans to be analyzed in a step-wise approach and anticipate path dependencies, which may pose as barriers for alternative pathways, more precisely in the decision-making process.

Following Haasnoot et al.'s seminal work, the adaptation pathways literature - which is most frequently applied to FRM - regularly features path dependency. Nonetheless it remains hard to identify the concept's role in ongoing debates and grasp its actual benefits. As pointed

\section{Budget pathway exposure pathway}

out by Parsons et al. (2019), the broad majority of publications reflects that "there is limited explanation of what the concept actually means in the context of environmental policy and climate change adaptation". Indeed, when path dependency is mentioned, it typically includes vague references to past decisions or claims such as 'history matters' (Sorensen 2015). Unsurprisingly, historians and social scientists acknowledge that the statement 'history matters' is an unhelpful and uncritical truism with no explanatory power (van Buuren et al. 2016). In many other instances, authors describe path dependencies as barriers to adaptation (Barnett et al. 2015; Burnham et al. 2016; Matthews et al. 2015; Smith \& Brown 2014), because they create lock-in effects that heavily confine following decisions, developments, and capabilities (Pauw \& Pegels 2013; Sheller \& León 2016) and lead to "policy traps" (Nair \& Howlett 2016). However, also these studies do not include any more detail on the concept and how it could be made operational.

Hanger-Kopp et al. (forthcoming) are the first to make this conceptual connection between backward- and forward-looking research on adaptation pathways in order to harness the full potential of the path dependency concept. For the operationalization of this combined historical-future perspective, they refer to examples from FRM in various European countries. The result is a novel approach, which suggests entry points for path dependency analysis at different steps of the APA and by extension the DAPP (Hanger-Kopp et al. forthcoming). This preceding work serves as fundament for the early identification of path dependencies in our local case studies.

Traditionally, the path dependency concept has been applied in the analysis of past developments. The APA however, is a forward-looking planning tool. We argue that an extended understanding of adaptation pathways allows scholars and practitioners to anticipate path dependencies, while at the same time it improves our understanding of the APA's limitations. The entry points for path dependency analysis we identified suggest to add 
the following steps at different stages in the APA or the DAPP: (i) Develop an understanding of the initial situation for path dependent development (including the actual decision to apply an APA or DAPP), (ii) anticipate contingent events which might kick off path dependent developments (e.g. significant events), (iii) consider potential alternative pathways, (iv) consider selfreinforcing mechanisms, and (v) create opportunities for internal change (which is crucial to overcome lock-in situations and, thus, avoid path dependencies).

\section{Reconstructing pathways taken and not taken - FRM in two Austrian case studie}

Based on this extension of the APA and the DAPP, we aimed at reconstructing pathways for two study sites in Austria: First, the Ennstal region in the federal state of Styria comprises the three municipalities of Sölk, Öblarn and Michaelerberg-Pruggern, where 4,800 inhabitants, living in dispersed rural settlements, spread over an area of ca. $400 \mathrm{~km}^{2}$. The region includes a wide range of different torrential rivers and the large river Enns. Severe flood events occurred in close sequence over the last decades, as in 2002 river floods from the river Enns affected the entire catchment, and various torrential flood events in 2010 , 2012, 2013 and 2017 hit specific municipalities. For example, the 2017 event alone caused 19.7 million Euro of damages in the Öblarn municipality. The Ennstal region is dominantly rural, where most citizens commute to larger urban districts close by. Others are working in the agricultural and tourism sector. The second study site, the Aist region in the federal state of Upper Austria, comprises two districts and 29 municipalities. The rural areas are located in the upper part of the catchment. A large proportion of the citizens commutes to the neighbouring urban agglomerations of Linz or Wels. Another large part of the local population is working in the forestry and agricultural sector. Larger urban settlements are located in the lower part of the catchment. They were highly affected by the 2002 river floods from the Aist river as well as several surface runoff events in the years 2009, 2013 and 2016. In particular, the various flood events mainly affected the downstream municipalities Schwertberg, Gutau, Tragwein and Pregarten (Thaler 2014; Thaler et al. 2016, 2017).

The two study sites were selected because they (1) recently experienced hydro-meteorological events; (2) are hazard-prone due to their topography and high accumulation of assets, and are likely to be affected by climate change; and (3) are already active in iterative risk management and resilience building, and possess a high risk awareness. In both study sites, we applied a mixedmethod approach: First, an extended document analysis looking back thirty years retrieved and reviewed flood event documentation, reports of flood risk management agencies and emergency rescue services, municipal newspapers, media reports, and other written sources. Events mentioned in these sources were compiled, checked for consistency and plausibility, and then listed historically as hazard pathway (the sequence of flood events and changes in exposure) and adaptation pathway (the sequence of structural and non-structural measures). These pathways were used as basis for semi-structured interviews with key stakeholders at the municipal, district and provincial level of government. The interviews aimed to operationalise the constitutive characteristics of path dependency; foremost whether suboptimality or inefficiency can be observed, and which self-reinforcing mechanisms were (or still are) at play. However, as an important methodological caveat, revisiting historical events and developments which occurred more than a decade ago proved difficult in the stakeholder interviews, as the respondent had fragmentary recollections, had been elected or promoted to their current position just recently, or could not elaborate on events beyond their personal jurisdiction.

In the Ennstal region, the adaptation pathway almost exclusively consists of structural measures such as dams or retention basins. Local mayors voluntarily hand over their discretionary power regarding the decisions about which measures should be implemented to the superordinate governance level of district and provincial authorities. The reasons are that mayors lack technical and administrative competencies, have more pressing matters on their day-to-day agenda, and are reluctant to take personal responsibility for allocating protection to selected settlement areas or to communicate residual risk to concerned citizens. Provincial authorities adhere to a rigid, predefined administrative process for financing and planning adaptive measures; while this process ensures legal security and legitimacy, it allows for little flexibility in adapting measures to local needs and tends to reproduce structural measures as the dominant problem-solving strategy, as these measures are established and uncontested. Catastrophic events, or a rapid sequence of events as 2010-2017 in Ennstal, act as triggers or decision points to spur local action. After the 2017 Ennstal event, district authorities drew on plans that were pre-prepared following the 2010 events and, thus, were able to react quickly to submit extensive measures for public financing and approval. Mayors are aware of impending risks but tend to proceed incrementally by alleviating the currently most urgent point of concern and focus on immediate reactions and short-term availability of funding schemes. They are relieved if superordinate governance actors offer readymade plans. Revisions of hazard maps are initiated and implemented by superordinate governance actors; instead of proactively co-designing these processes, local mayors remain in a passive role. As policy leverage is concentrated at superordinate levels, this level is also the entry point for paradigm shifts in flood risk management, as e.g. introduced by European flood directives.

In the Aist region, we identified the 2002 river flood event as key event. From an APA-perspective, it can be interpreted as contingent event that started a pathway, because it was followed by the regional development of a catchment-wide management plan. The original plan foresaw the use of a natural flood management strategy, such as floodplain restoration, river restoration, the implementation of upland water retention and storage areas, etc., as extension to the planned linear structural measures (Thaler et al. 2016). The management concept 
foresaw, for example, the implementation of 25 retention basins across the whole catchment - with the key aim to reduce the risk of the downstream municipalities. A catchment-wide inter-communal co-operation was implemented with the aim of implementing catchmentbased measures at privately owned land in the upstream municipalities, while downstream municipalities provide large parts of the financial compensation (Thaler et al. 2016; 2017; 2020). Additionally, the inter-local cooperation included a series of structural measures along the river Aist. Overall, it must be said that the FRM-adaptation pathway was exclusively planned and implemented by the national and regional water authorities, such as Austrian Service for Torrent and Avalanche Control and Federal Water Engineering Administration. Both organisations are the leading actors in Austrian FRM. They have the knowledge, expertise and power to influence the current policy and strategy within the Aist region. The local authorities play an important role in terms of providing financial resources for the flood alleviation schemes, negotiating with private land-owners, and developing local strategies to response to flood hazards. However, their interests and contributions depended strongly on whether or not they are involved in the decision-making process (part of the management construct within the inter-local co-operation) as well as their individual risk awareness and perception. The inter-local co-operation took over tasks from the local municipalities, such as communication and maintenance of the flood alleviation schemes. However, as policy leverage is mainly concentrated at national and regional levels (similar to the Ennstal study site), mainly because these authorities started and organised the catchment-wide management plan, the main tasks for the inter-local co-operation remained the negotiation with private land-owners. However, they were not too successful: After 13 years of negotiation, the region was able to implement only a very small number of flood storages across the catchment. The implementation of structural measures and small-scale natural flood management strategies remained much more significant.

\section{Conclusions and outlook for FRM}

This paper is a contribution to ongoing debates in FRM in two regards: First, it confirms that FRM-practice has not yet responded to the theoretical call for more flexible and comprehensive risk governance approaches that make society more resilient against potential future events. Second, it suggests that a more profound integration of knowledge about and experiences with past pathways into forward-looking planning is a promising input to develop these approaches.

Our analysis focused on the long-term development and impacts of decision-making arenas in two regions in Austria. Based on these case studies, it became obvious that Austrian FRM is heavily dominated by top-down policies. Strategic long-term planning, if there is any, is allocated at the federal state level. The Austrian Service for Torrent and Avalanche Control and Federal Water Engineering Administration are leading FRM in terms of planning, implementation, funding, and the provision of policy guidelines. Local authorities are very much occupied with their everyday agenda. They would be overwhelmed if they were asked to develop and advance pathways. This particularly applies to small rural municipalities who lack workforce that is experienced in FRM. Furthermore, their policy planning horizon hardly extends beyond a mayor's term of office. Accordingly, local authorities usually play a minor role within the planning and decision-making process. Their main tasks are the provision of up to 20 per cent of the funding of flood protection projects as well as costs of maintenance, and negotiation with private land owners to pave the way for the implementation of structural measures. Nevertheless, inter-local co-operations, such as proven by the Aist example, have the potential to improve the interaction with federal authorities. The main reason might be their resources that are specifically dedicated for FRM, such as for hiring external experts.

Overall, Austrian FRM can still be labelled as an accumulation of structural and non-structural measures that are or were based on previous hazard events (single or a series of events). We observe a purely reactive instead of a preventive approach. In addition to the above-mentioned institutional shortcomings at the local level, this might also be a result of limited interaction between the disaster risk management and the climate change adaptation policy domains. While the former has a stronger backwardlooking and reactive approach that lacks anticipatory risk management planning (Nordbeck et al. 2019), the latter focuses heavily on future developments of climate-related risks. We suggest a much stronger integration of these two policy domains, operationalized by means of a comprehensive climate risk management framework (see e.g. Leitner et al. 2020; Schinko et al. 2016), which corresponds with a generally stronger integration of backward- with forward-looking perspectives. Our analysis showed that it is hard to confirm path dependency empirically if adaptation measures are implemented in a haphazard, ad-hoc manner. However, the diffusion of responsibility from local authorities to actors at higher levels of government, who tend to replicate established approaches, can definitely be identified as potential selfreinforcing mechanism incurring path dependency. This observation shows that, even if it is a methodological challenge to revisit historical events and developments which occurred more than a decade ago, it might be worth to trace past pathways that led to particular constellations and decision-making situations as a sound foundation for the development of socioeconomically and politically feasible flood risk management pathways for the future.

\section{Acknowledgments}

This research was funded by the Austrian Climate and Energy Fund and was carried out within the Austrian Climate Research Program (project number B960201).

\section{References}

1. Babcicky, P., Seebauer, S. (2017): The two faces of social capital in private flood mitigation: Opposing 
effects on risk perception, self-efficacy and coping capacity. Journal of Risk Research, 20(8), 1017-1037.

2. Barnett, J., Evans, L.S., Gross, C., Kiem, A.S., Kingsford, R.T., Palutikof, J.P., Pickering, C.M., Smithers, S.G. (2015): From barriers to limits to climate change adaptation: path dependency and the speed of change. Ecol. Soc. 20, art5.

3. Bloemen, P., Reeder, T., Zevenbergen, C., Rijke, J., Kingsborough, A. (2018): Lessons learned from applying adaptation pathways in flood risk management and challenges for the further development of this approach. Mitigation and Adaptation Strategies for Global Change, 23(7), 1083-1108.

4. Burnham, M., Ma, Z., Endter-Wada, J., Bardsley, T. (2016): Water Management Decision Making in the Face of Multiple Forms of Uncertainty and Risk. $J$. Am. Water Resour. Assoc. 52, 1366-1384.

5. Ciullo, A., Kwakkel, J.H., De Bruijn, K.M., Doorn, N., Klijn, F. (2020): Efficient or Fair? Operationalizing Ethical Principles in Flood Risk Management: A Case Study on the Dutch-German Rhine. Risk Anal. 40, 1844-1862.

6. Clar, C. (2019): Coordinating climate change adaptation across levels of government: the gap between theory and practice of integrated adaptation strategy processes. Journal of Environmental Planning and Management 62(12), 2166-2185.

7. Clar, C., Steurer, R. (2019): Climate change adaptation at different levels of government: characteristics and conditions of policy change. Natural Resources Forum 43(2), 121-131.

8. Collenteur, R., de Moel, H., Jongman, B., Di Baldassarre, G. (2014): The failed-levee effect: Do societies learn from flood disasters? Natural Hazards, 76(1), 373-388.

9. Fuchs, S., Röthlisberger, V., Thaler, T., Zischg, A., Keiler, M. (2017): Natural hazard management from a co-evolutionary perspective: exposure and policy response in the European Alps. Annals of the American Geographers, 107(2), 382-392.

10. Fuchs, S., Thaler, T. (2017): Tipping points in natural hazard risk management: How societal transformation can provoke policy strategies in mitigation. Journal of Extreme Events, 4(1), 1750006, 1-21.

11. Haasnoot, M., Kwakkel, J.H., Walker, W.E., ter Maat, J. (2013): Dynamic adaptive policy pathways: A method for crafting robust decisions for a deeply uncertain world. Global Environmental Change, 23(2), 485-498.

12. Haasnoot, M., Van Deursen, W.P.A., Middelkoop, H., Van Beek, E., Wijermans, N. (2012): An Integrated Assessment MetaModel for developing adaptation pathways for sustainable water management in the lower Rhine Delta. Presented at the iEMSs 2012 Managing Resources of a Limited Planet: Proceedings of the 6th Biennial Meeting of the International Environmental Modelling and Software Society, 1743-1751.

13. Hanger-Kopp, S., Thaler, T., Schinko, T., Seebauer, S., Lückl, A., Clar, C. (forthcoming): The ability of adaptation pathways to reveal or anticipate path dependencies. Under review.

14. Kates, R.W., Travis, W.R., Wilbanks. T.J. (2012): Transformational adaptation when incremental adaptations to climate change are insufficient. Proceedings of the National Academy of Sciences of the United States of America, 109(19), 7156-7161.

15. Kwadijk, J.C.J., Haasnoot, M., Mulder, J.P.M., Hoogvliet, M.M.C., Jeuken, A.B.M., van der Krogt, R.A.A., van Oostrom, N.G.C., Schelfhout, H.A., van Velzen, E.H., van Waveren, H., de Wit, M.J.M. (2010): Using adaptation tipping points to prepare for climate change and sea level rise: a case study in the Netherlands. Wiley Interdisciplinary Reviews: Climate Change, 1, 729-740.

16. Leitner, M., Babcicky, P., Schinko, T., Glas, N. (2020): The status of Climate Risk Management in Austria. Assessing the governance landscape and proposing ways forward for comprehensively managing flood and drought risk. Climate Risk Management 30: el00246. DOI:10.1016/j.crm.2020.100246.

17. Matthews, T., Lo, A.Y., Byrne, J.A. (2015): Reconceptualizing green infrastructure for climate change adaptation: Barriers to adoption and drivers for uptake by spatial planners. Landsc. Urban Plan. 138, 155-163.

18. Nair, S., Howlett, M. (2016): From robustness to resilience: avoiding policy traps in the long term. Sustain. Sci. 11, 909-917.

19. Nordbeck, R., Steurer, R., Löschner, L. (2019): The future orientation of Austria's flood policies: from flood control to anticipatory flood risk management.

20. Papathoma-Kohle, M., Gems, B., Sturm, M., Fuchs, S. (2017): Matrices, curves and indicators: A review of approaches to assess physical vulnerability to debris flows. Earth Sciences Reviews, 171, 272-288.

21. Parsons, M., Nalau, J., Fisher, K., Brown, C. (2019): Disrupting path dependency: Making room for Indigenous knowledge in river management. Glob. Environ. Change 56, 95-113.

22. Pauw, P., Pegels, A. (2013): Private sector engagement in climate change adaptation in least developed countries: an exploration. Clim. Dev. 5, 257-267.

23. Prettenthaler, F., Kortschak, D., Hochrainer-Stigler, S., Mechler, R., Urban, H., Steininger, K.W. (2015): Catastrophe management: Riverine flooding, Chapter 18 in Steininger, K.W., König, M., Bednar-Friedl, B., Kranzl, L., Loibl, W., Prettenthaler, F. (eds.): Economic evaluation of climate change impacts: Development of a cross-sectoral framework and results for Austria. Berlin: Springer, 349-366.

24. Ranger, N., Reeder, T., Lowe, J. (2013): Addressing 'deep' uncertainty over long-term climate in major infrastructure projects: four innovations of the Thames Estuary 2100 Project. EURO J. Decis. Process. 1, 233-262.

25. Schinko, T., Mechler, R., Hochrainer-Stigler, S. (2016): Developing a methodological framework for operationalizing Iterative Climate Risk Management based on insights from the case of Austria. Mitigation 
and Adaptation Strategies for Global Change 22: 1063-1086.

26. Seebauer, S., Babcicky, P. (2016): Alles oder nichts oder doch eine Versicherung? Umsetzungsbereitschaft für Eigenmaßnahmen gegen Hochwasser in steirischen und Vorarlberger Haushalten. Proceedings from Understanding Risk Austria, 28-29.

27. Seebauer, S., Ortner, S., Babcicky, P., Thaler, T. (2019): Bottom-up citizen initiatives as emergent actors in flood risk management: Mapping roles, relations and limitations. Journal of Flood Risk Management, 12(3), e12468.

28. Sheller, M., León, Y.M. (2016): Uneven socioecologies of Hispaniola: Asymmetric capabilities for climate adaptation in Haiti and the Dominican Republic. Geoforum 73, 32-46.

29. Smith, A.M., Brown, M.A. (2014): Policy Considerations for Adapting Power Systems to Climate Change. Electr. J. 27, 112-125.

30. Sorensen, A. (2015): Taking path dependence seriously: an historical institutionalist research agenda in planning history. Plan. Perspect. 30, 17-38.

31. Stauffacher, M., Flüeler, T., Krütli, P., Scholz, R.W. (2008): Analytic and dynamic approach to collaboration: A transdisciplinary case study on sustainable landscape development in a Swiss prealpine region. Systemic Practice and Action Research, 21(6), 409-422.

32. Sturm, M., Gems, B., Keller, F., Mazzorana, B., Fuchs, S., Papathoma-Kohle, M., Aufleger, M. (2018): Experimental analyses of impact forces on buildings exposed to fluvial hazards. Journal of Hydrology, 565, 1-13.

33. Tarlock, A.D. (2012): United States flood control policy: The incomplete transition from the illusion of total protection to risk management. Duke Environmental Law \& Policy Forum, 23, 151-183.

34. Thaler, T. (2014): Developing partnership approaches for flood risk management: implementation of interlocal co-operations in Austria. Water International, 6(4), 929-944.

35. Thaler, T., Priest, S.J., Fuchs, S. (2016): Evolving inter-regional co-operation in flood risk management: distances and types of partnership approaches in Austria. Regional Environmental Change, 16, 841853.

36. Thaler, T., Löschner, L., Hartmann, T. (2017): The introduction of catchment-wide co-operations: Scalar reconstructions and transformation in Austria in flood risk management. Land Use Policy, 68, 563-573.

37. Thaler, T., Attems, M.-S., Bonnefond, M., Clarke, D., Gatien-Tournat, A., Gralepois, M., Fournier, M., Murphy, C., Rauter, M., Papathoma-Kohle, M., Servain, S., Fuchs, S. (2019): Drivers and barriers of adaptation initiatives - How societal transformation affects natural hazard management and risk mitigation in Europe. Science of the Total Environment, 650, 1073-1082.

38. Thaler, T., Seebauer, S. (2019): Bottom-up citizen initiatives in natural hazard management: Why they appear and what they can do? Environmental Science \& Policy, 94, 101-111.

39. Thaler, T., Doorn, N., Hartmann, T. (2020): Justice of compensation for spatial flood risk management comparing the flexible Austrian and the structured Dutch approach. Die Erde, 151(2-3), 104-115.

40. Tseng, C.P., Penning-Rowsell, E.C. (2012): Micropolitical and related barriers to stakeholder engagement in flood risk management. The Geographical Journal, 178(3), 253-269.

41. van Buuren, A., Ellen, G.J., Warner, J. (2016): Pathdependency and policy learning in the Dutch delta: toward more resilient flood risk management in the Netherlands? Ecol. Soc. 21.

42. Wise, R.M., Fazey, I., Stafford Smith, M., Park, S.E., Eakin, H.C., Archer Van Garderen, E.R.M., Campbell, B. (2014): Reconceptualising adaptation to climate change as part of pathways of change and response. Glob. Environ. Change 28, 325-336.

43. Zandvoort, M., Campos, I.S., Vizinho, A., PenhaLopes, G., Krkoska Lorencova, E., van der Brugge, R., van der Vlist, M.J., van den Brink, A., Jeuken, A.B.M. (2017): Adaptation pathways in planning for uncertain climate change: Applications in Portugal, the Czech Republic and the Netherlands. Environmental Science \& Policy, 78, 18-26. 